\title{
Buckling of Two-Dimensional Covalent Organic Frameworks Under Thermal Stress
}

\author{
Austin M. Evans ${ }^{1}$, Matthew R. Ryder ${ }^{2}$, Nathan C. Flanders ${ }^{1}$, Edon Vitaku ${ }^{1}$, \\ Lin X. Chen ${ }^{1,3}$, and William R. Dichtel ${ }^{1 *}$ \\ ${ }^{1}$ Department of Chemistry, Northwestern University, \\ 2145 Sheridan Road, Evanston, Illinois 60208, USA \\ ${ }^{2}$ Neutron Scattering Division, Oak Ridge National Laboratory, \\ Oak Ridge, Tennessee 37831, USA \\ ${ }^{3}$ Chemical Sciences and Engineering Division, Argonne National Laboratory, \\ Argonne, Illinois 60439, USA
}

\section{Supplementary Information}

\section{Correspondence Address}

Professor William R. Dichtel

Department of Chemistry

Northwestern University

2145 Sheridan Road

Evanston, IL 60208 (USA)

wdichtel@northwestern.edu 


\section{Table of Contents}

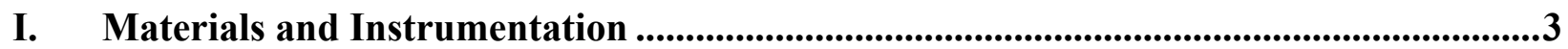

II. Experimental Procedures and Characterization of COF Monomers..............................5

III. Experimental Procedures of COF Syntheses .........................................................8

IV. FT-IR of Covalent Organic Frameworks ....................................................................

V. CP-MAS ${ }^{13} \mathrm{C}$ NMR Spectra of Covalent Organic Frameworks ..................................11

VI. X-Ray Diffraction of Covalent Organic Frameworks.....................................................13

VII. Nitrogen Isotherms of Covalent Organic Frameworks ..................................................15

VIII.Pore Size Distributions of Covalent Organic Frameworks ..........................................17

IX. Density Functional Theory Calculations ................................................................................19

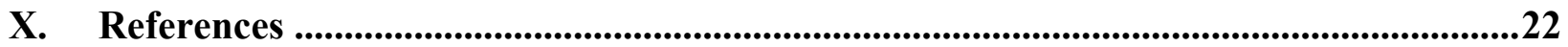




\section{Materials and Instrumentation}

\section{Materials}

Dry dichloromethane (DCM) was obtained by passing previously degassed solvents through activated alumina columns. All other reagents were purchased from commercial sources and used without further purification or prepared from them. Reactions were monitored by thin layer

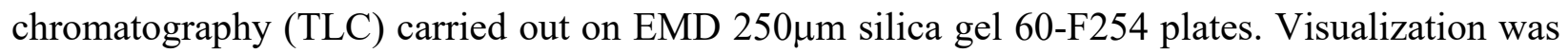
performed by UV light irradiation and potassium permanganate stain and heat.

\section{Instrumentation}

Nuclear Magnetic Resonance. ${ }^{1} \mathrm{H}$ and ${ }^{13} \mathrm{C}$ NMR spectra were acquired on Bruker AvanceIII-500 $\mathrm{MHz}$ equipped with a DHC CryoProbe and recorded at $25^{\circ} \mathrm{C}$. The spectra were calibrated using residual solvent as internal reference $\left(\mathrm{CDCl}_{3}: 7.26 \mathrm{ppm}\right.$ for ${ }^{1} \mathrm{H} \mathrm{NMR}, 77.00$ for $\left.{ }^{13} \mathrm{C} \mathrm{NMR}\right)$. Solid state ${ }^{13} \mathrm{C}$ CP/MAS NMR spectra of covalent organic frameworks were recorded on a Varian 400 $\mathrm{MHz}$ at a spin rate of $10,000 \mathrm{~Hz}$ and calibrated using adamantane as an external standard.

Infrared Spectroscopy. Infrared spectra were recorded on a Nicolet iS10 FT-IR spectrometer equipped with a diamond ATR attachment and are uncorrected.

High-Resolution Mass Spectrometry. High-resolution mass spectra were acquired on Agilent 6210A LC-TOF Mass Spectrometer, with Atmospheric Pressure Photoionization (APPI) as an ionization source. The instrument is equipped with an Agilent Series 1200 HPLC binary pump, and Autosampler, using Mass Hunter software. The samples were run using direct injection.

Microwave Reactor. Microwave reactions were performed on a CEM Discover SP unit, operating at $110 \mathrm{~V}$, with microwave irradiation of $2.45 \mathrm{GHz}$, and a maximum microwave output of $300 \mathrm{~W}$ in $10 \mathrm{~mL}$ capacity Teflon-capped tubes. All reactions were performed using the "standard" method, where only the temperature point and run times were controlled. 
Gas Adsorption. Gas adsorption isotherms were conducted on a Micromeritics ASAP 2420 Accelerated Surface Area and Porosity Analyzer. Typically, 20-50 mg samples were transferred to dried and tared analysis tubes equipped with filler rods and capped with a Transeal. The samples were heated to $40{ }^{\circ} \mathrm{C}$ at a rate of $1{ }^{\circ} \mathrm{C} / \mathrm{min}$ and evacuated at $40{ }^{\circ} \mathrm{C}$ for $20 \mathrm{~min}$, then heated to 100 ${ }^{\circ} \mathrm{C}$ at a rate of $1{ }^{\circ} \mathrm{C} / \mathrm{min}$ heat, and evacuated at $100{ }^{\circ} \mathrm{C}$ until the outgas rate was $\leq 0.3 \mu \mathrm{mHg} / \mathrm{min}$ (holding the samples at $100{ }^{\circ} \mathrm{C}$ for 5 hours was sufficient), at which point the tube was weighed again to determine the mass of the activated sample. The tube was then transferred to the analysis port of the instrument. Ultra-high-purity-grade (99.999\% purity) $\mathrm{N}_{2}$ was used for all adsorption measurements. $\mathrm{N}_{2}$ isotherms were generated by incremental exposure to nitrogen up to $760 \mathrm{mmHg}$ $(1 \mathrm{~atm})$ in a liquid nitrogen $(77 \mathrm{~K})$ bath. Oil-free vacuum pumps and oil-free pressure regulators were used for all measurements. Brunauer-Emmett-Teller (BET) surface areas were calculated from the linear region of the $\mathrm{N}_{2}$ isotherm at $77 \mathrm{~K}$ within the pressure range $P / P_{0}$ of $0.05-0.10$.

In Operando X-ray Diffraction Studies. In operando X-ray diffraction was performed at sector 17 of the Advanced Photon Source, Argonne National Laboratory. Samples were prepared by packing $\sim 25 \mathrm{mg}$ of COF sample into a thick-walled Kapton capillary and mounted into a sample holder available at the Sector 17. A thermocouple was then mounted in the center of the powder sample, inside of the Kapton capillary. The sample was then placed under a constant stream of helium and heated at a rate of $10{ }^{\circ} \mathrm{C} \mathrm{min}^{-1}$ under a helium atmosphere. Diffraction patterns were collected over the course of this heating on a 2D Pilatus detector approximately every minute by collecting ten frames per minute and averaging the counts of these ten frames. These frames were then radially integrated to produce 1D diffraction patterns, which were then analyzed.

Thermogravimetric Analysis. Thermogravimetric analysis (TGA) was performed on a Netzch Simultaneous Thermal Analysis (STA) system using approximately $5 \mathrm{mg}$ of sample. The samples were heated to a designated temperature at a rate of $10{ }^{\circ} \mathrm{C} \mathrm{min}^{-1}$ under a helium atmosphere.

Sonication. Sonication was performed with a Branson 3510 ultrasonic cleaner with a power output of $100 \mathrm{~W}$ and a frequency of $42 \mathrm{kHz}$. 


\section{Experimental Procedures and Characterization of COF Monomers}

Benzophenoneimine of benzidine (BND-Benzophenone). ${ }^{1}$ To a $500 \mathrm{~mL}$ flame-dried roundbottom flask, benzidine (5.10 g, $27.75 \mathrm{mmol}, 1.0$ equiv), benzophenone (10.11 g, $55.50 \mathrm{mmol}, 2.0$ equiv), 1,4-diazobicyclo[2.2.2] octane (DABCO) (18.69 g, $166.50 \mathrm{mmol}, 6.0$ equiv), and chlorobenzene $(300 \mathrm{~mL})$ were added and the contents were stirred at room temperature under a nitrogen atmosphere. Titanium (IV) chloride (4.56 mL, $41.64 \mathrm{mmol}, 1.5$ equiv) was syringed in portions over $15 \mathrm{~min}(1 / 4$ of the portion at times $0 \mathrm{~min}, 5 \mathrm{~min}, 10 \mathrm{~min}$, and $15 \mathrm{~min})$. After the addition was complete, the reaction mixture was stirred for another $20 \mathrm{~min}$ at room temperature, then the flask was equipped with a reflux condenser, and the reaction stirred at $125{ }^{\circ} \mathrm{C}$ overnight $(12 \mathrm{~h})$. The reaction mixture was then cooled to about $40{ }^{\circ} \mathrm{C}$ and filtered while warm through a Buchner funnel equipped with a filter paper. The filtrate was then concentrated in vacuo. The crude product was purified by stirring in hot absolute ethanol/chloroform mixture $(\sim 3: 1, \sim 1200 \mathrm{~mL})$, performing a hot filtration through a cotton-plugged plastic funnel, and allowing the filtrate to slowly cool to room temperature, at which point the product crystallized. The flask was then further cooled in a refrigerator overnight. The solid was then collected and dried to give the product as a yellow/orange solid ( $8.22 \mathrm{~g}, 58 \%$ yield).

${ }^{1}$ H NMR (500 MHz, $\left.\mathbf{C D C l}_{3}\right) \delta 7.76-7.70(\mathrm{~m}, 4 \mathrm{H}), 7.47-7.41$ (m, 2H), 7.38 (dd, $J=8.3,6.7$ $\mathrm{Hz}, 4 \mathrm{H}), 7.33-7.29(\mathrm{~m}, 4 \mathrm{H}), 7.28-7.20(\mathrm{~m}, 6 \mathrm{H}), 7.15-7.08(\mathrm{~m}, 4 \mathrm{H}), 6.78-6.68(\mathrm{~m}, 4 \mathrm{H})$.

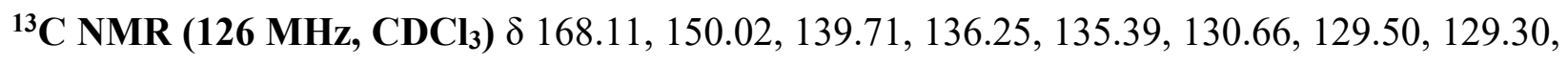
$128.58,128.16,128.02,127.97,126.55,121.45$.

Triformylphloroglucinol was prepared according to a reported procedure, and its NMR spectra was consistent with those previously reported. ${ }^{2}$ 

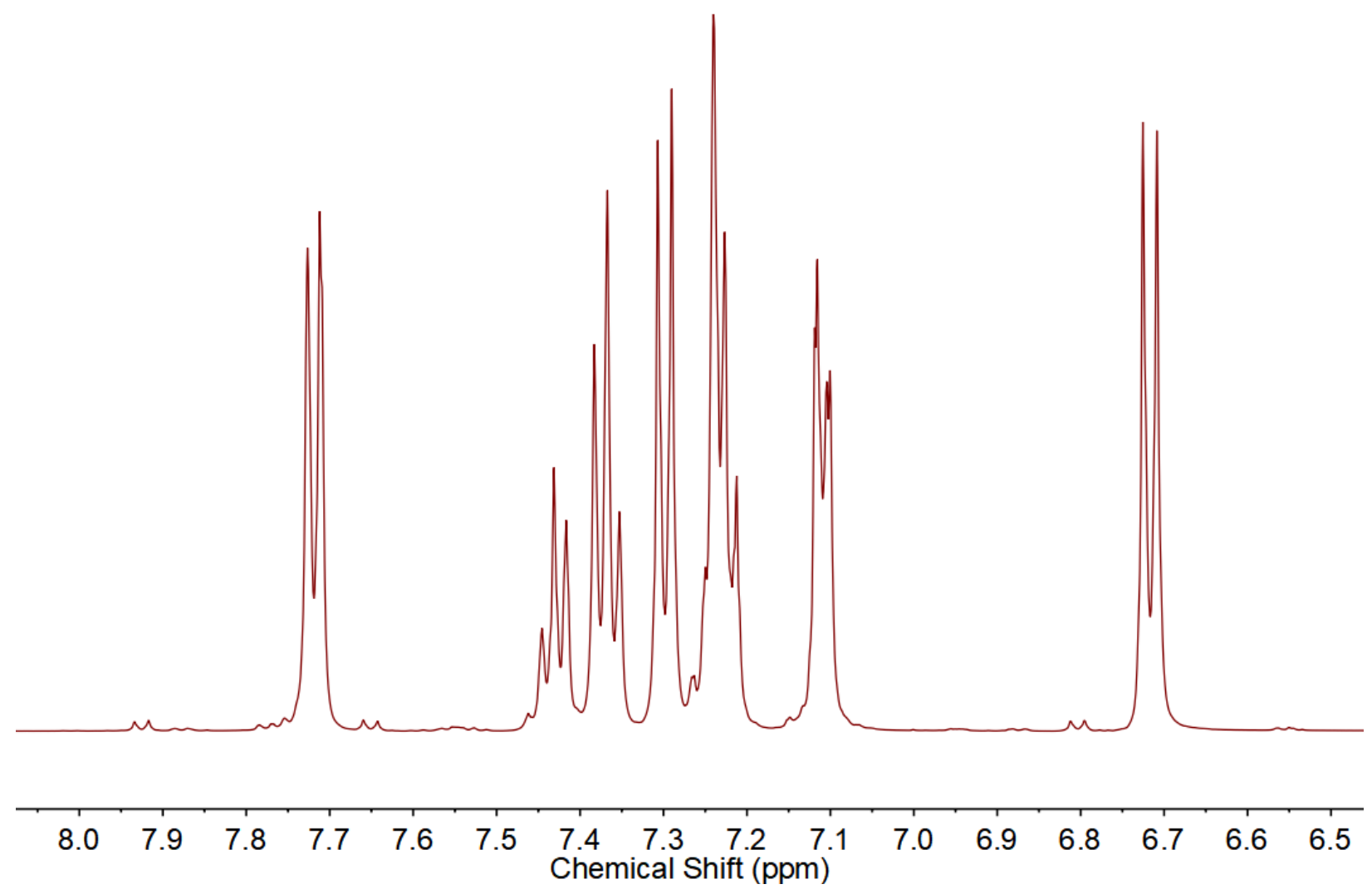

Figure S1. ${ }^{1} \mathrm{H}$ NMR spectrum (500 MHz, $\mathrm{CDCl}_{3}$, $298 \mathrm{~K}$ ) of BND-Benzophenone. 


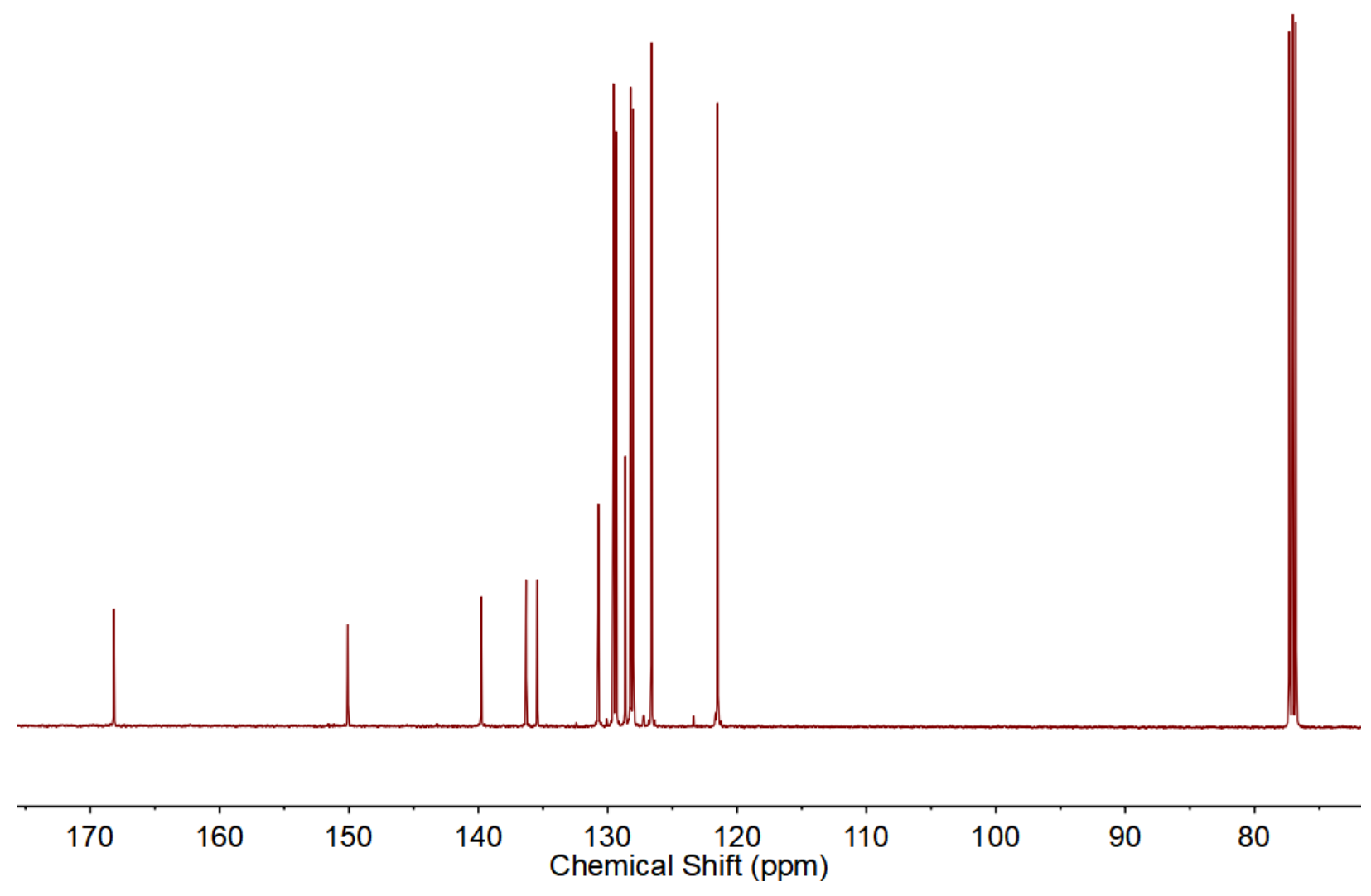

Figure S2. ${ }^{13} \mathrm{C}$ NMR spectrum $\left(126 \mathrm{MHz}, \mathrm{CDCl}_{3}, 298 \mathrm{~K}\right)$ of BND-Benzophenone. 


\section{Experimental Procedures for COF Syntheses}

BND-TFB COF: To a flame-dried $250 \mathrm{~mL}$ high-pressure flask with vacuum valve, 1,3,5triformylbenzene $(0.97 \mathrm{~g}, 6.0 \mathrm{mmol}, 1.5 \mathrm{equiv})$ and benzidine-benzophenone $(4.61 \mathrm{~g}, 9.0 \mathrm{mmol}$, 1.5 equiv) were added, followed by mesitylene:dioxane $(1: 1,60.0 \mathrm{~mL})$ along the walls of the flask (to push down any remaining solids remaining atop of the flask). The flask was sealed and sonicated at room temperature for $10 \mathrm{~min}$, and then $6 \mathrm{M}$ acetic acid $(10 \mathrm{~mL})$ was added, and the flask was sealed again. The reaction mixture was then degassed through three freeze-pump-thaw cycles (vacuum $<50$ mTorr), after which the vacuum valve was switched to $\mathrm{N}_{2}$, and the flask was charged with $\mathrm{N}_{2}$ and sealed under positive $\mathrm{N}_{2}$ pressure. The flask was then placed (no stirring) in a $120^{\circ} \mathrm{C}$ pre-heated oil bath for three days. The flask was removed from the oil bath, allowed to cool, and filtered through a Buchner funnel equipped with a filter paper. Acetone was used to ensure all of the material is filtered from the flask to the Buchner funnel. The solid was collected and stirred in an Erlenmeyer flask in hot DMF (600 $\mathrm{mL}$ at $90{ }^{\circ} \mathrm{C}$ for $\left.30 \mathrm{~min}\right)$, and filtered while hot. This procedure was repeated two more times in DMF $\left(600 \mathrm{~mL}\right.$ at $90{ }^{\circ} \mathrm{C}$ for $\left.30 \mathrm{~min}\right)$, once in absolute ethanol $\left(600 \mathrm{~mL}\right.$ at $80{ }^{\circ} \mathrm{C}$ for $\left.30 \mathrm{~min}\right)$, and lastly once in acetone $\left(600 \mathrm{~mL}\right.$ at $\left.60{ }^{\circ} \mathrm{C}\right)$. The material was then filtered, collected, placed in a vacuum chamber and dried at $120{ }^{\circ} \mathrm{C}$ for $24 \mathrm{~h}$ under vacuum to give an orange solid $(1.98 \mathrm{~g}, 86 \%)$.

BND-TFP COF: To a flame-dried $150 \mathrm{~mL}$ high-pressure flask with vacuum valve, triformylphloroglucinol (0.63 g, $3.0 \mathrm{mmol}, 1.0$ equiv) and BND-TFB COF (1.15 g, $3.0 \mathrm{mmol}, 1.0$ equiv) were added, followed by mesitylene:dioxane $(1: 1,30.0 \mathrm{~mL})$ along the walls of the flask (to push down any remaining solids remaining atop of the flask). The flask was sealed and sonicated at room temperature for $10 \mathrm{~min}$, and then $6 \mathrm{M}$ acetic acid $(5 \mathrm{~mL})$ was added, and the flask was sealed again. The reaction mixture was then degassed through three freeze-pump-thaw cycles (vacuum $<50$ mTorr), after which the vacuum valve was switched to $\mathrm{N}_{2}$, and the flask was charged with $\mathrm{N}_{2}$ and sealed under positive $\mathrm{N}_{2}$ pressure. The flask was then placed (no stirring) in a $120^{\circ} \mathrm{C}$ pre-heated oil bath for three days. The flask was removed from the oil bath, allowed to cool, and filtered through a Buchner funnel equipped with a filter paper. Acetone was used to ensure all of the material is filtered from the flask to the Buchner funnel. The solid was collected and stirred in 
an Erlenmeyer flask in hot DMF $\left(600 \mathrm{~mL}\right.$ at $90{ }^{\circ} \mathrm{C}$ for $\left.30 \mathrm{~min}\right)$ and filtered while hot. This procedure was repeated two more times in DMF $\left(600 \mathrm{~mL}\right.$ at $90{ }^{\circ} \mathrm{C}$ for $\left.30 \mathrm{~min}\right)$, once in absolute ethanol $\left(600 \mathrm{~mL}\right.$ at $80^{\circ} \mathrm{C}$ for $\left.30 \mathrm{~min}\right)$, and lastly once in acetone $\left(600 \mathrm{~mL}\right.$ at $\left.60{ }^{\circ} \mathrm{C}\right)$. The material was then filtered, collected, placed in a vacuum chamber and dried at $120^{\circ} \mathrm{C}$ for $24 \mathrm{~h}$ under vacuum to give a red solid $(1.25 \mathrm{~g}, 97 \%)$. 
IV. FT-IR Spectra of Covalent Organic Frameworks

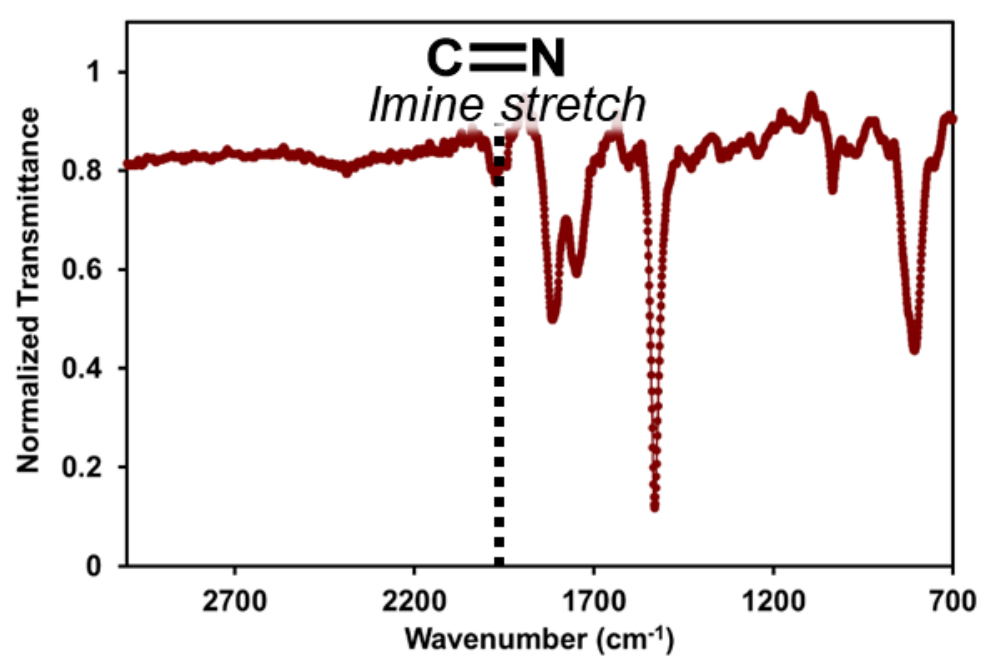

Figure S3. FT-IR spectrum of BND-TFB COF

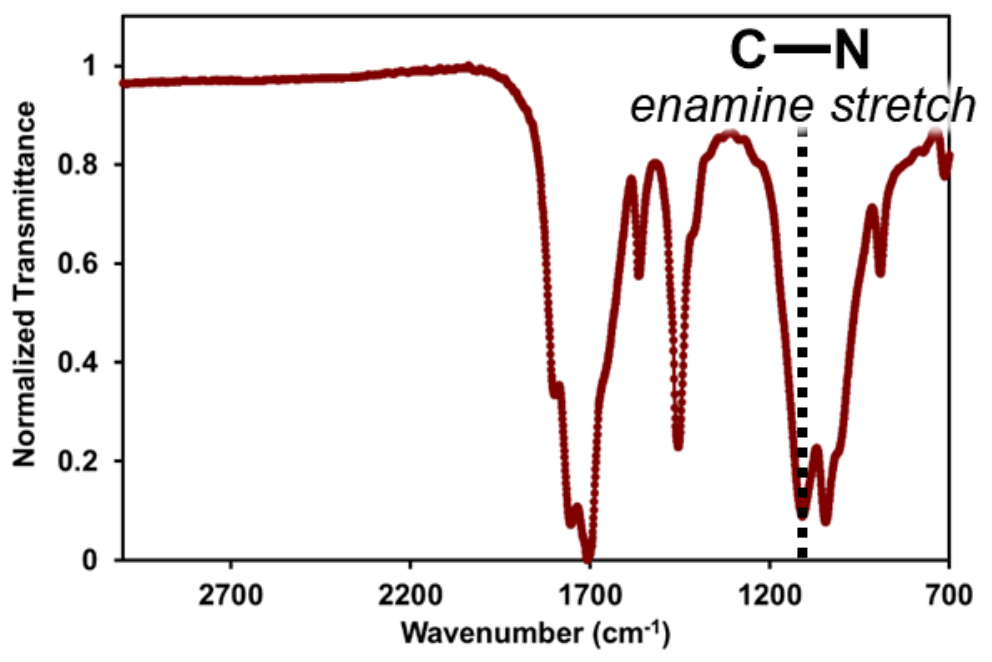

Figure S4. FT-IR spectrum of BND-TFP COF 


\section{CP-MAS ${ }^{13} \mathrm{C}$ NMR Spectra of COFs}

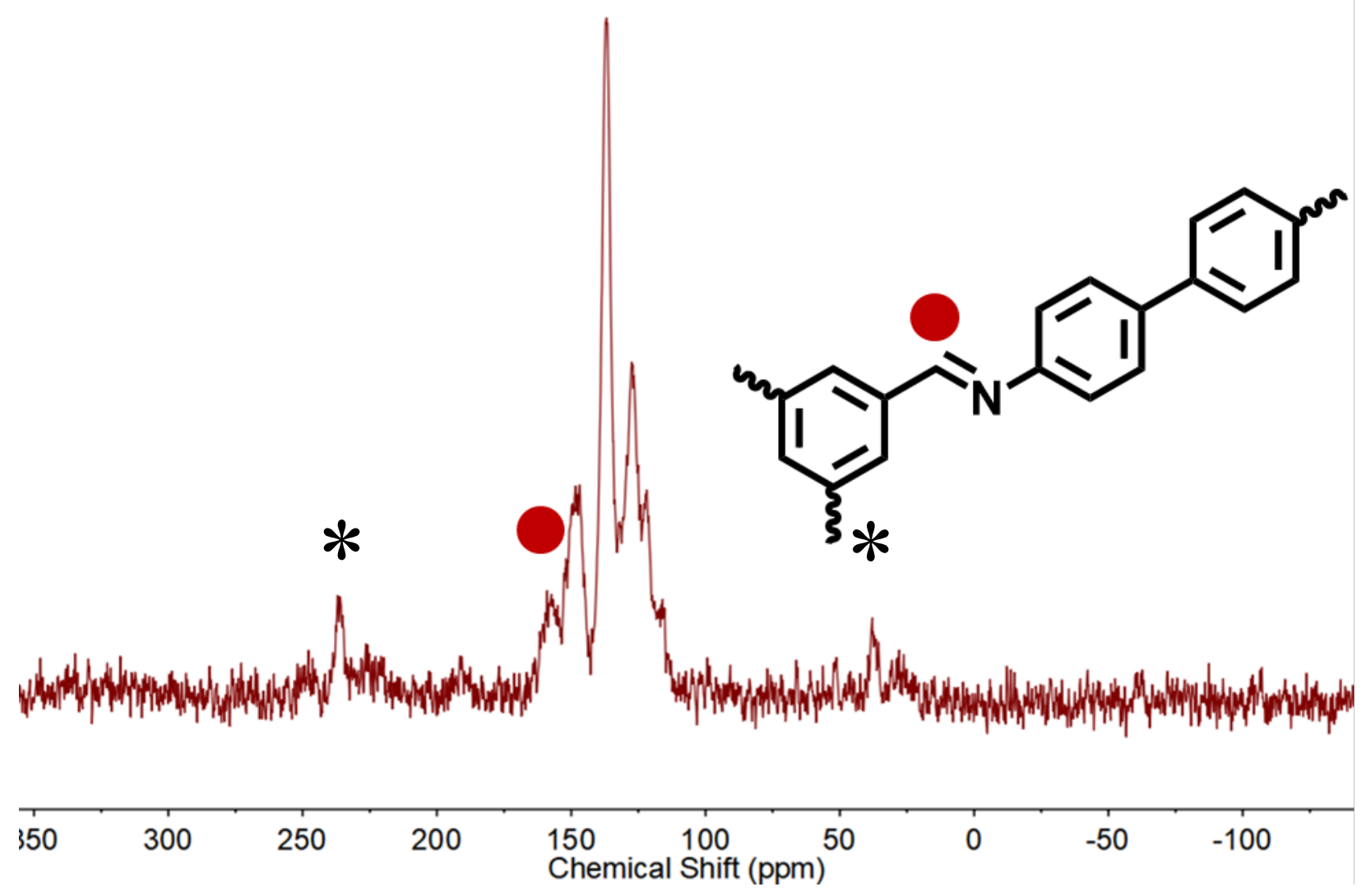

Figure S5. CP-MAS ${ }^{13} \mathrm{C}$ NMR spectrum of BND-TFB COF.

Spinning side bands are denoted by “*”. 


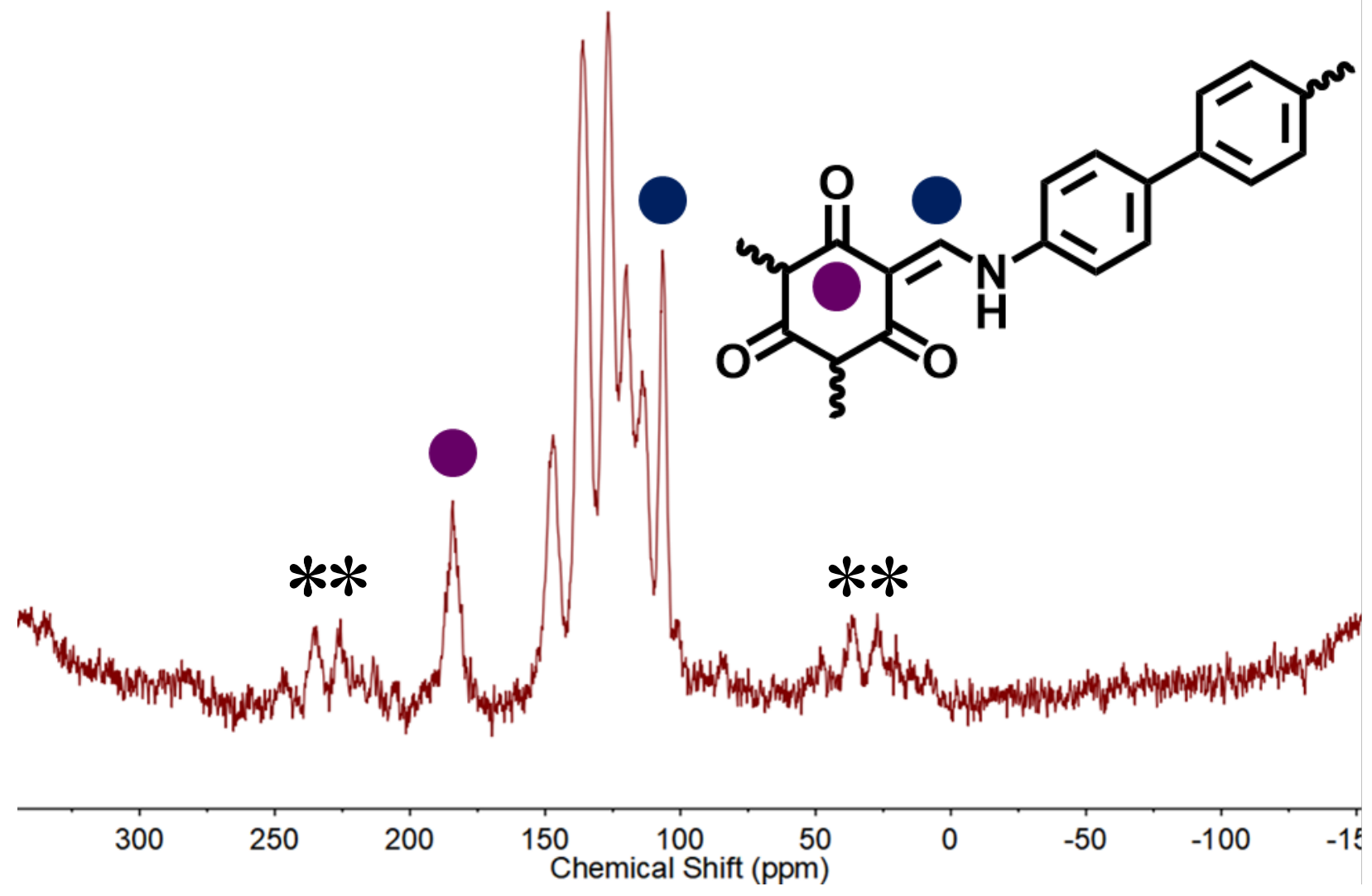

Figure S6. CP-MAS ${ }^{13} \mathrm{C}$ NMR spectrum of BND-TFP COF.

Spinning side bands are denoted by “*” 
VI. X-ray Diffraction of Covalent Organic Frameworks

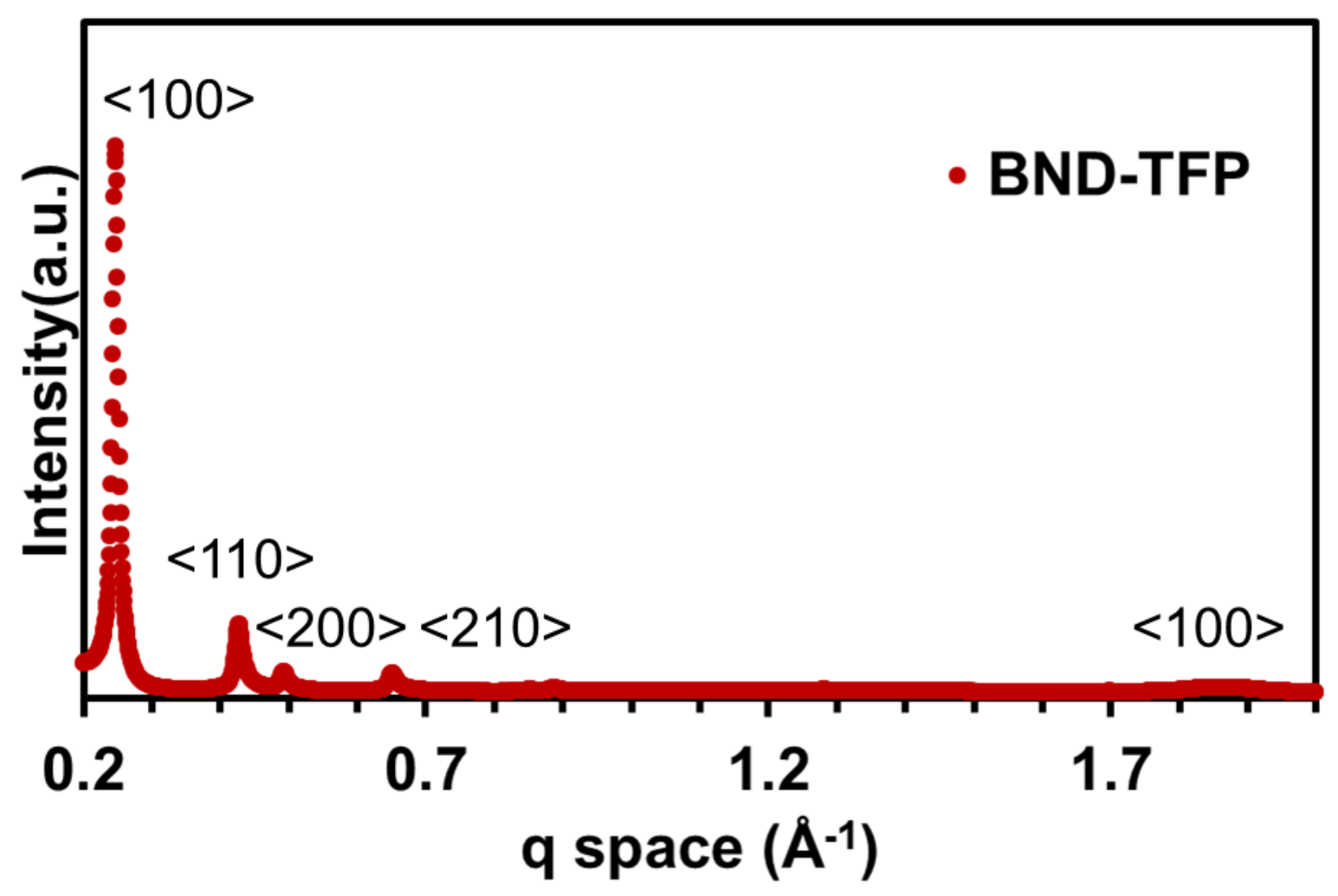

Figure S7. Room temperature x-ray diffraction pattern of BND-TFP COF 


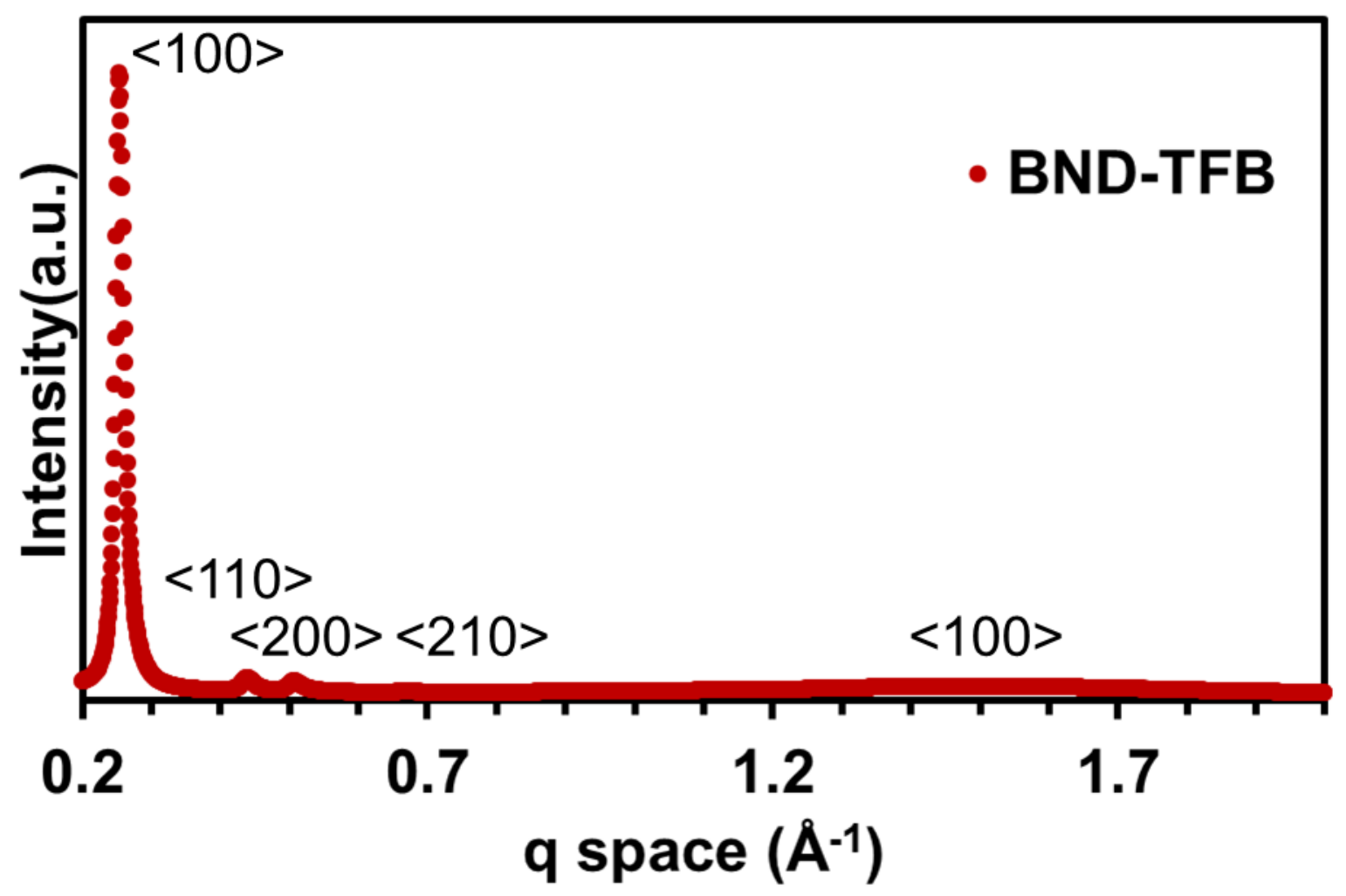

Figure S8. Room temperature x-ray diffraction pattern of BND-TFB COF 
VII. Nitrogen Isotherms of Covalent Organic Frameworks

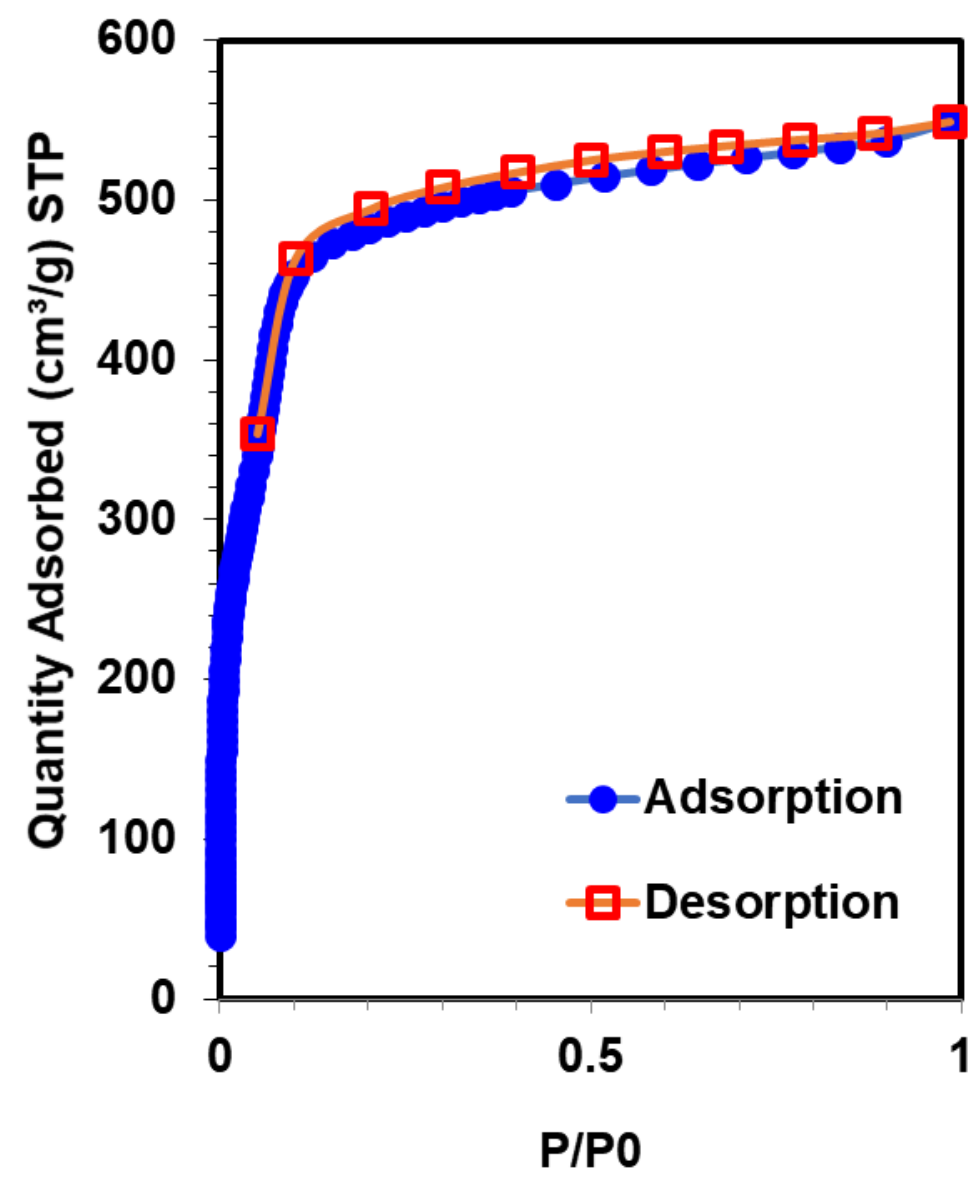

Figure S9. Nitrogen isotherm of BND-TFP COF 


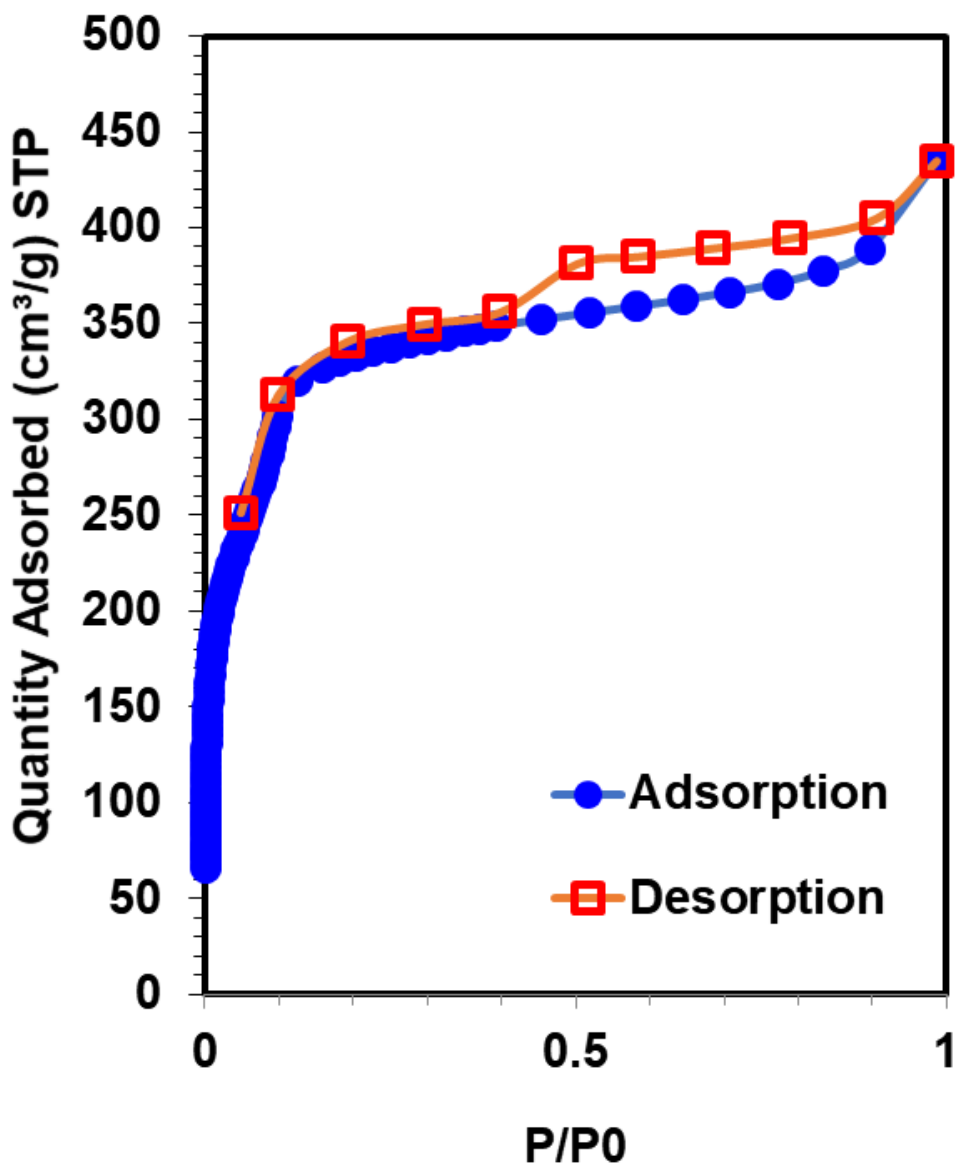

Figure S10. Nitrogen isotherm of BND-TFB COF 
VIII. Pore Size Distributions of Covalent Organic Frameworks

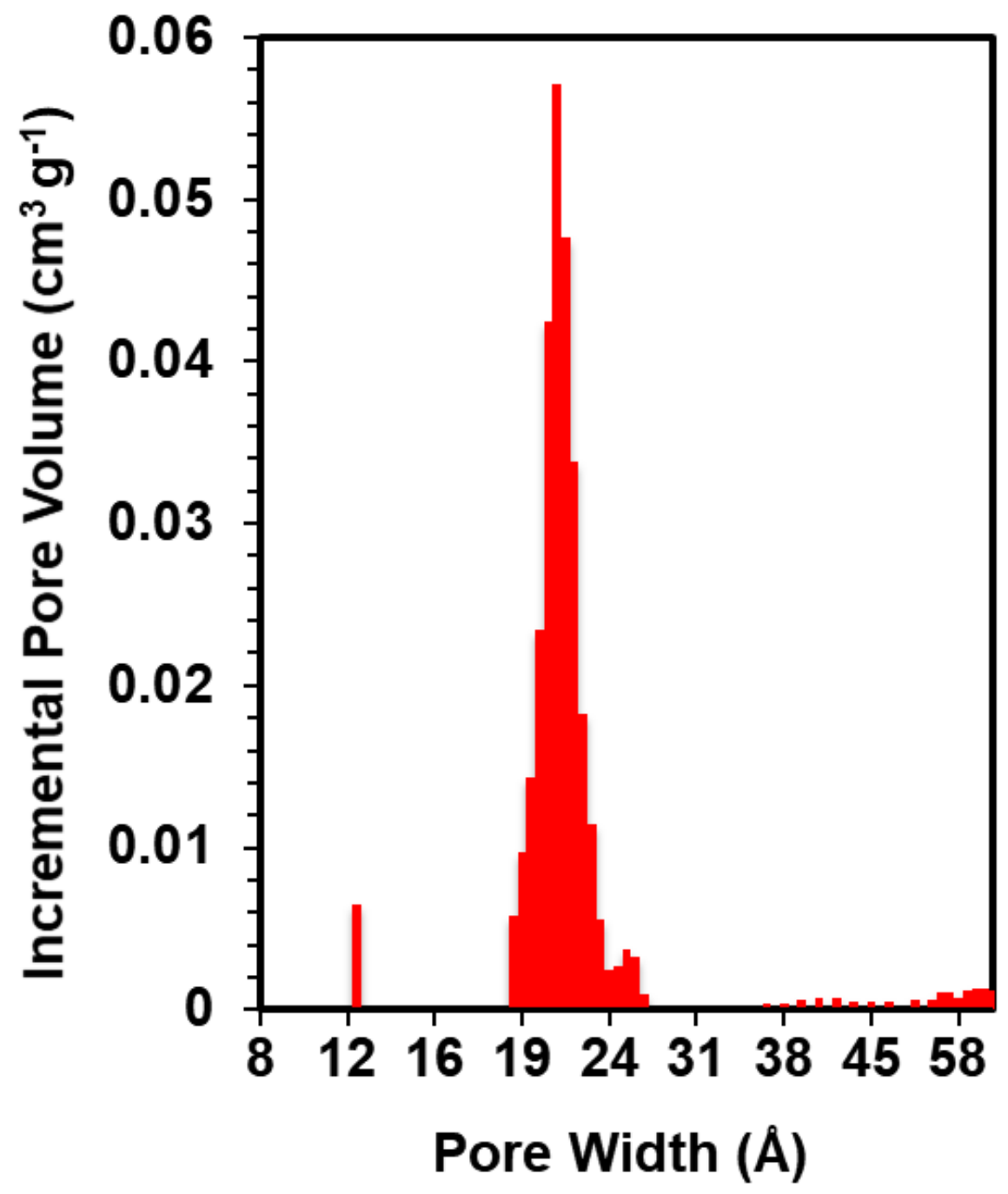

Figure S11. Pore size distribution of BND-TFP COF 


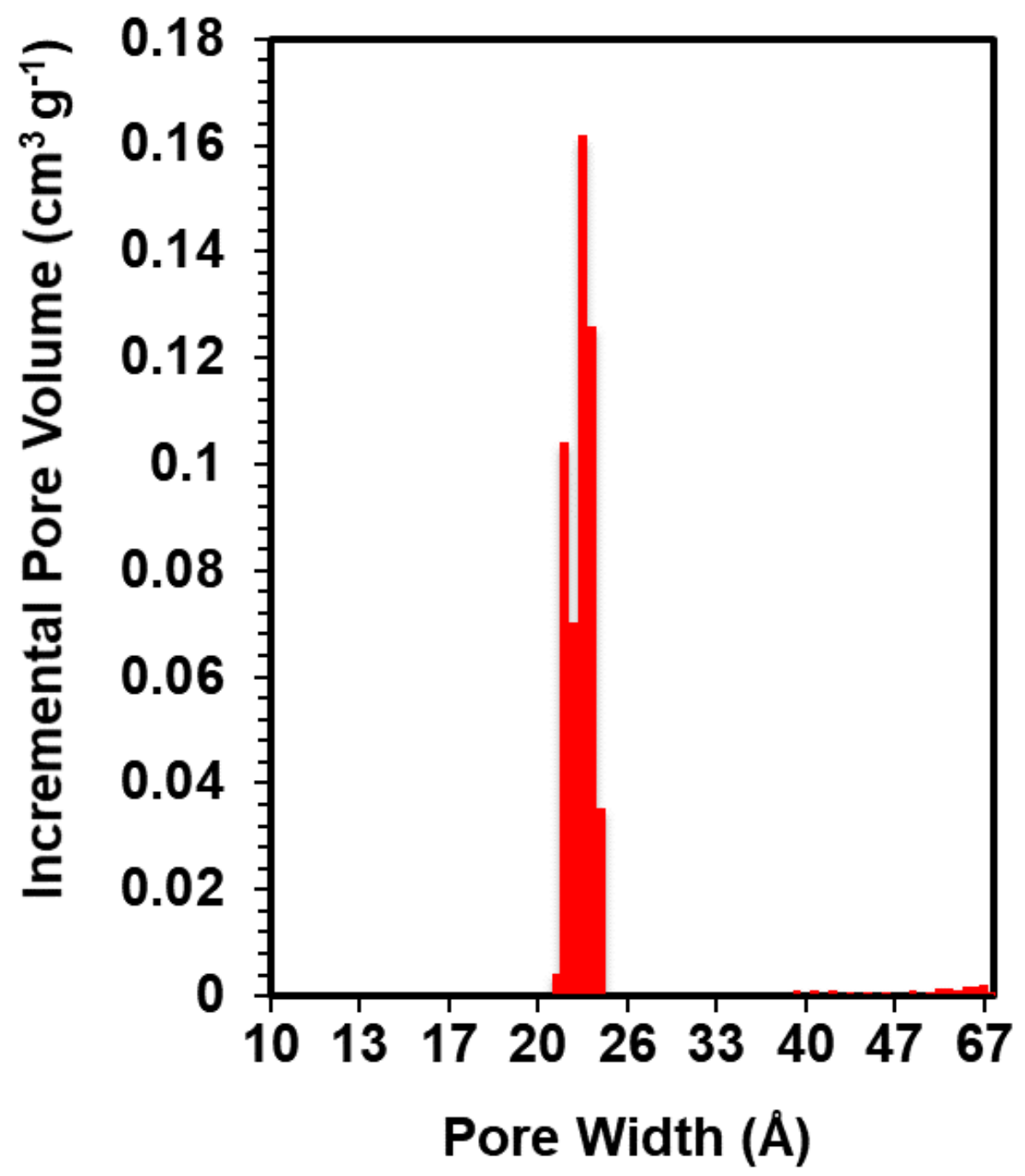

Figure S12. Pore size distribution of BND-TFB COF 


\section{Density Functional Theory (DFT) Calculations}

Density functional theory (DFT) calculations were performed using the periodic ab initio code CRYSTAL17. ${ }^{3-4}$ The PBE exchange-correlation functional ${ }^{5}$ was used with a semi-classical dispersion correction (PBE-D3) ${ }^{6}$ to better account for the noncovalent interactions present in the 2D COF structures. The dispersion correction includes a BJ damped pairwise and three-body term to the DFT energies. ${ }^{6}$ Each of the DFT calculations was performed with all-electron atom-centered Gaussian-type basis sets of double-zeta quality, similar to previous work on the electronic properties and dielectric response of other porous materials. ${ }^{7}$

The all-electron basis sets contained a total of 1,128 basis functions, corresponding to 450 electrons spread over 378 shells per unit cell for BND-TFP. The lattice parameters and atomic coordinates were optimized while maintaining the space group symmetry $(P \sigma)$ via a quasiNewtonian algorithm. ${ }^{8-12}$ The optimization was considered to have converged when the maximum and root-mean-square (RMS) gradient, and the maximum and RMS atomic displacements were simultaneously below $1.5 \times 10^{-5}, 1.0 \times 10^{-5}, 3.0 \times 10^{-5}$ and $2.0 \times 10^{-5}$ a.u., respectively.

Table S1. Summary of the calculated lattice parameters for BND-TFP.

\begin{tabular}{|c|c|c|c|c|}
\hline \hline \multirow{2}{*}{ Phase } & \multicolumn{4}{|c|}{ Lattice parameters $(\AA)$} \\
\cline { 2 - 5 } & $a$ & $b$ & 3.61 & $\beta$ \\
\hline Planar & 30.03 & 30.03 & 3.60 & 120.0 \\
\hline Buckled & 29.97 & 29.54 & 122.2 \\
\hline - The planar and buckled geometries have hexagonal and monoclinic symmetry respectively. \\
\hline
\end{tabular}

The structural stability of BND-TFP upon compression was investigated using a similar procedure to that recently reported for MOF $-5^{13}$ by computing the energy at various optimized volumetrically constrained geometries and fitting the curve to an equation of state (EOS). ${ }^{14}$ The bulk modulus values reported in the main text (Figure S13) were obtained from fitting the curve to a third-order isothermal Birch-Murnaghan EOS. ${ }^{15}$ A series of volumetrically contracted and expanded geometries were investigated ranging from $-10 \%$ to $+4 \%$ and the resultant energy curve is shown in Figure S14. Within the experimental symmetry confinements of the initial structure $(P 6)$, the optimized equilibrium geometry was the most energetically favorable (minimum energy). 


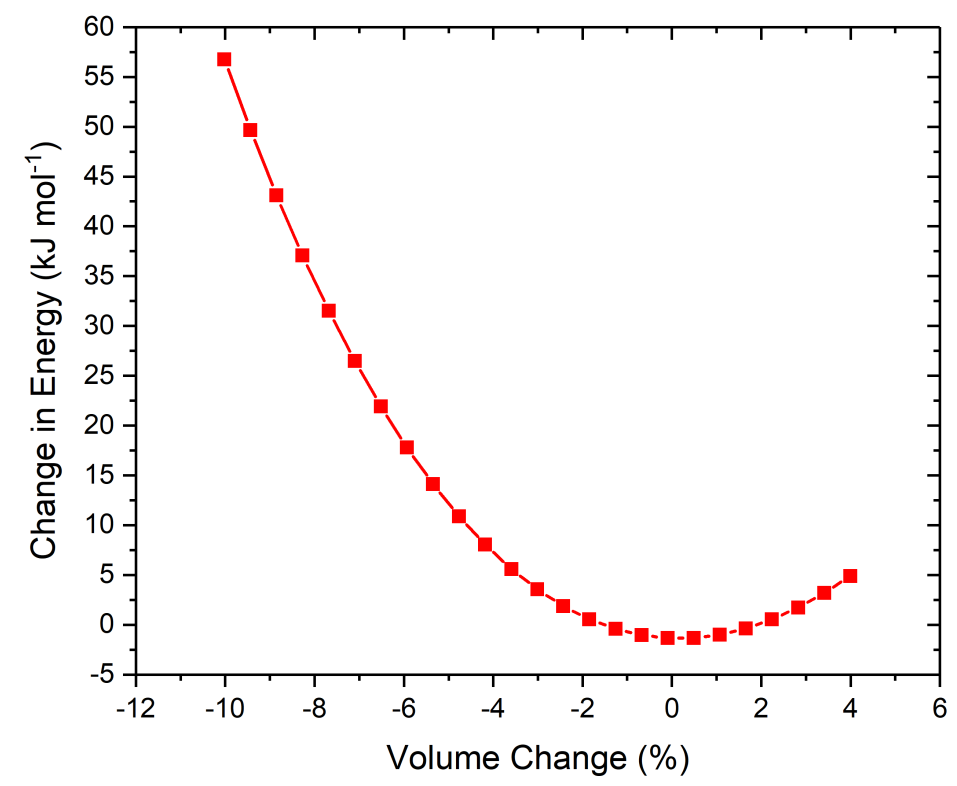

Figure S13. Change in energy upon compression an expansion with constant symmetry (PØ).

However, upon further analysis of the volumetrically constrained geometries, the low-energy phonon modes were seen to soften as a function of compression, both with and without the correction for dispersion interactions (PBE and PBE-D3), and were imaginary for the PBE-D3 results indicating the possibility of a symmetry-reduced phase transition. The PBE-D3 results more accurately capture the inter-layer interactions and hence identify the phase instability at lower levels of compression compared to PBE. However, to calculate the specific level of compression required to induce the phase transition upon pressure, further investigation is needed. The size of the basis sets and number of radial and angular points defined for the integration grid were observed to affect the imaginary nature of the soft mode, and an in-depth analysis is out with the scope of the current work. To obtain structural insight into the new phase of BND-TFP, we analyzed the geometrical changes along the trajectory of the imaginary phonon mode and allowing for the associated symmetry reduction relaxed the resultant structure to optimize to the 'buckled' phase. The infrared (IR) absorption spectra of the optimized planar and buckled phases of BNDTFP are reported in Figure S15. The IR intensities were computed through the Berry Phase approach, ${ }^{16}$ by evaluating the Born atomic tensors as polarization differences between the original and the distorted geometries. ${ }^{17-18}$ In the range of $650-3500 \mathrm{~cm}^{-1}$, the spectral features did not change significantly in either position or intensity, in good agreement with experiment (Figure $\mathrm{S} 15)$. Therefore, the slight shift in the experimental signal around $1600 \mathrm{~cm}^{-1}$ is likely due to thermal 
expansion of the lattice which is omitted from the computed spectra. Therefore, the vibrational modes involved do not appear to be significantly affected by the change from the planar to the buckled phase. The presence of multiple phases made analyzing the linear thermal response of the crystalline lattice over a broad range challenging and will be investigated further in a more indepth computational study.

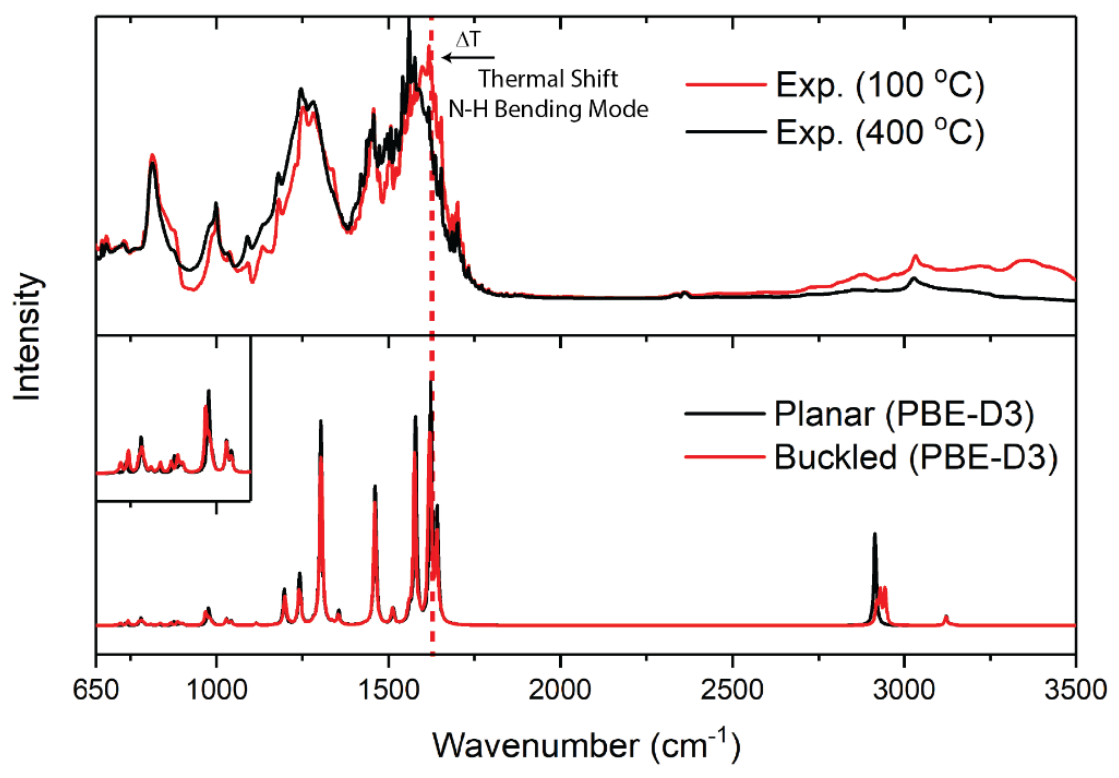

Figure S14. IR spectra of the planar and buckled phase of BND-TFP.

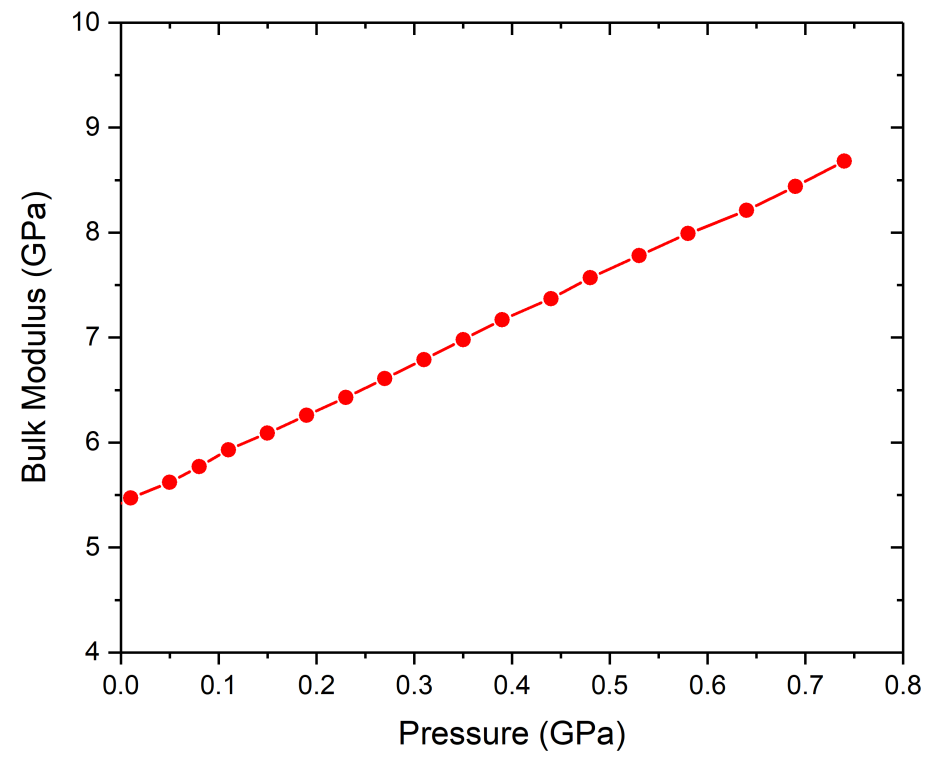

Figure S15. Bulk modulus as a function of pressure. Structural stiffening of BND-TFP occurs upon compression. 


\section{References}

1. Vitaku, E.; Dichtel, W. R., J. Am. Chem. Soc. 2017, 139, 12911-12914.

2. Chong, J. H.; Sauer, M.; Patrick, B. O.; MacLachlan, M. J., Org. let. 2003, 5, 3823-3826.

3. Dovesi, R.; Saunders, V. R.; Roetti, C.; Orlando, R.; Zicovich-Wilson, C. M.; Pascale, F.; Civalleri, B.; Doll, K.; Harrison, N. M.; Bush, I. J.; D’Arco, P.; Llunell, M.; Causà, M.; Noël, Y.; Maschio, L.; Erba, A.; Rerat, M.; Casassa, S., CRYSTAL17 User's Manual (University of Torino) 2017.

4. Dovesi, R.; Erba, A.; Orlando, R.; Zicovich-Wilson, C. M.; Civalleri, B.; Maschio, L.; Rerat, M.; Casassa, S.; Baima, J.; Salustro, S.; Kirtman, B., Wires Comput Mol Sci 2018, 8, e1360.

5. Perdew, J. P.; Burke, K.; Ernzerhof, M., Phys. Rev. Lett. 1996, 77, 3865-3868.

6. Grimme, S.; Antony, J.; Ehrlich, S.; Krieg, H., J. Chem. Phys. 2010, 132, 154104.

7. Ryder, M. R.; Donà, L.; Vitillo, J. G.; Civalleri, B., ChemPlusChem 2018, 83, 308-316.

8. Broyden, C. G., J. Inst. Maths Applics 1970, 6, 76-90.

9. Broyden, C. G., J. Inst. Maths Applics 1970, 6, 222-231.

10. Fletcher, R., Comput. J. 1970, 13, 317-322.

11. Goldfarb, D., Math. Comput. 1970, 24, 23-26.

12. Shanno, D. F., Math. Comput. 1970, 24, 647-656.

13. Ryder, M. R., et al., Submitted.

14. Erba, A.; Mahmoud, A.; Belmonte, D.; Dovesi, R., J. Chem. Phys. 2014, 140, 124703.

15. Birch, F., J. Geophys. Res. 1952, 57, 227-286.

16. Noel, Y.; Zicovich-Wilson, C. M.; Civalleri, B.; D’Arco, P.; Dovesi, R., Phys. Rev. B 2001, 65 .

17. Dovesi, R.; Orlando, R.; Erba, A.; Zicovich-Wilson, C. M.; Civalleri, B.; Casassa, S.; Maschio, L.; Ferrabone, M.; De La Pierre, M.; D'Arco, P.; Noel, Y.; Causa, M.; Rerat, M.; Kirtman, B., Int. J. Quantum Chem. 2014, 114, 1287-1317.

18. Ryder, M. Physical phenomena in metal-organic frameworks: mechanical, vibrational, and dielectric response. University of Oxford, 2017. 